Table 2 Asthma diary card scores for last 28 days of each treatment period

\begin{tabular}{lrcrrr}
\hline & \multicolumn{2}{l}{ Clemastine } & & \multicolumn{2}{l}{ Placebo } \\
\cline { 2 - 3 } \cline { 5 - 6 } \cline { 5 - 6 } & Mean & Range & & Mean & Range \\
\hline Symptom score & $61 \cdot 9$ & $12-147$ & $62 \cdot 1$ & $12-138$ \\
Symptom-free days & $8 \cdot 3$ & $0-23$ & $8 \cdot 5$ & $0-17$ \\
Doses of bronchodilator & $77 \cdot 1$ & $8-260$ & $81 \cdot 4$ & $0-203$ \\
PEFR (1/m) & & & & \\
$\quad$ Morning & 274 & $174-475$ & 264 & $156-486$ \\
$\quad$ Evening & 288 & $200-482$ & 288 & $186-504$ \\
\hline
\end{tabular}

falls from baseline in PEFR and $\mathrm{FEV}_{0.75}$ of $31 \%$ and $36 \%$ respectively, compared with falls after placebo of $33 \%$ both for PEFR and FEV F.75 $_{\text {. }}$.

We could not find any significant clinical benefit from clemastine as judged by symptom scores, asthma-free days, total bronchodilator usage, or twice-daily PEFR measurements at home (Table 2). The strongest trend noted was that 9 of the 15 children used fewer doses of salbutamol and other bronchodilators during the active period.

\section{Discussion}

Clemastine in a dose of $200 \mu \mathrm{g}$ delivered by metered aerosol was a bronchodilator in these children. Our findings are similar to those reported by Norgrady et al. ${ }^{1}$ in adult asthmatics in whom the maximum effect was reached slowly. In this study we did not find a significant improvement from baseline in $\mathrm{FEV}_{\mathbf{0 . 7 5}}$ until one hour after inhalation of clemastine (Table 1). This makes it unlikely that clemastine would ever find a role in the management of acute asthma in childhood.

We observed non-significant trends for the active drug period to be associated with less use of the bronchodilators, higher average morning PEFR at home, and higher baseline values for PEFR and $\mathrm{FEV}_{0.75}$ in the respiratory laboratory. However, the overall results of the clinical trial (Table 2) are discouraging with regard to the efficacy of the specific $\mathrm{H}_{1}$ receptor antagonist as treatment for chronic asthma. Only one child was strikingly better on clemastine than placebo. He was matched by 2 others who showed the reverse trend. Furthermore, the poor clinical response at home was probably not due to inadequate dosage and poor inhalation technique because we were able to measure significant bronchodilatation when the children used the metered aerosol in the respiratory laboratory.

Although we have shown that clemastine is a bronchodilator in a group of children with residual symptoms despite conventional treatment for asthma, this study does not suggest that clemastine will be a useful addition to the management of their asthma.

We gratefully acknowledge financial support from the Asthma Research Council, Sandoz, and the Nestle Paediatric Travelling Fellowship (Australia).

\section{References}

1 Nogrady S G, Hartley J P R, Handslip P D J, Hurst N P. Bronchodilatation after inhalation of the antihistamine clemastine. Thorax 1978; 33: 479-82.

2 Groggins R C, Milner A D, Stokes G M. Bronchodilator effects of clemastine, ipratropium bromide, and salbutamol in preschool children with asthma. Arch Dis Child 1981; 56: 342-4.

3 Hodges I G C, Milner A D, Stokes G M. Bronchodilator effect of two inhaled antihistamines, clemastine and chlorpheniramine, in wheezy school children. $\mathrm{Br} J$ Dis Chest 1983: in press.

4 Cogswell J J, Hull D, Milner A D, Norman A P, Taylor B. Lung function in childhood. 1. The forced expiratory volumes in healthy children using a spirometer and reverse plethysmograph. Br J Dis Chest 1975; 69: 40-50.

5 Cotes J E. Lung function assessment and application in medicine, third edition. Oxford: Blackwell, 1975: 345.

Correspondence to Professor A D Milner, Department of Child Health, University Hospital, Queens's Medical Centre, Nottingham NG7 2UH.

Received 16 December 1982

\title{
Relation between faecal fat and energy in preterm infants
}

\section{O G BROOKE AND CAROLE WOOD}

\section{Department of Child Health, St George's Hospital, London}

SUMMARY The energy measured in the faeces correlated highly $(r=0.93)$ with faecal fat in 111 24-hour stool collections from 37 preterm infants. It is easier to measure faecal energy than faecal fat, and energy measurements provide a better indication of nutrient malabsorption than faecal fat alone.
Impaired energy balance and low energy digestibility are common in preterm infants. ${ }^{12}$ This is likely to be due mainly to fat malabsorption, but faecal energy is also derived from unabsorbed or endogenous protein and carbohydrate. The energy content of the faeces is fairly easy to measure by ballistic bomb calorimetry, ${ }^{3}$ whereas faecal fat 


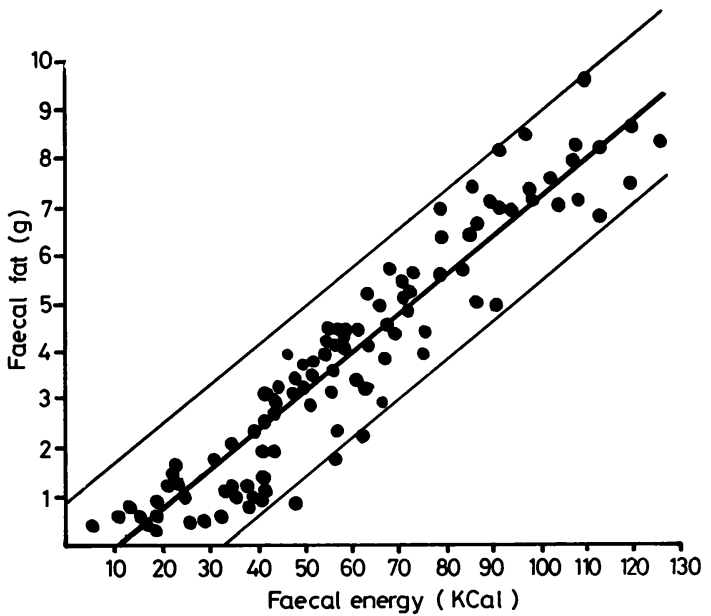

Figure Correlation between faecal fat and faecal energy in 111 24-hour stool collections from 37 preterm infants.

estimations are cumbersome and probably less accurate owing to difficulties with extraction procedures. The purpose of this investigation was to determine whether fat is indeed the major contributor to faecal energy, since calorimetry could then be used to estimate the degree of fat malabsorption.

\section{Methods}

Three-day stool collections were made in 37 preterm infants (mean birthweight $1436 \mathrm{~g}$, SD 317, gestation $32 \cdot 3$ weeks, SD 2.2). Stools were collected on polyester napkin liners (Boots) and stored frozen while awaiting analysis. Each day's collection was aggregated, weighed, freeze-dried, and homogenised with a grinder. Aliquots were then used for determination of energy by ballistic bomb calorimetry, ${ }^{1}$ and fat by a Soxhlet gravimetric method. ${ }^{4}$

\section{Results}

The figure shows the correlation between faecal fat and energy, with the $95 \%$ confidence limits. The correlation coefficient is $+0.93(\mathrm{P}<0.001)$. A given faecal energy determination will predict faecal fat to an accuracy of approximately $\pm 1 \mathrm{~g}$.

\section{Discussion}

It is apparent that fat is the major constituent of faecal energy in preterm infants and faecal fat content can be predicted with a fair degree of accuracy from faecal energy measurements. For the purposes of research faecal energy is probably more useful than faecal fat, unless fat absorption is specifically under investigation, since it provides data on the overall degree of energy malabsorption, which can then be used to calculate the difference between dietary energy and faecal losses.

\section{References}

1 Brooke O G, Alvear J, Arnold M. Energy retention, energy expenditure, and growth in healthy immature infants. Pediatr Res 1979; 13: 215-20.

2 Brooke $O$ G. Energy balance and metabolic rate in preterm infants fed with standard and high-energy formulas. Br J Nutr 1980; 44: 13-23.

3 Miller D S, Payne P R. A ballistic bomb calorimeter. Br J Nutr 1959; 13: 501-8.

4 Zuckerman J L, Zymaris M C, Natelson S. Simple method for the determination of fecal fat and fatty acids. $J$ Lab Clin Med 1949; 34: 282-6.

Correspondence to Dr O G Brooke, Department of Child Health, St George's Hospital Medical School, Cranmer Terrace, London SW17 ORE.

Received 13 January 1983

\title{
Cryptic mediastinal masses causing airways obstruction
}

\author{
D K C COOPER, A R CHRISPIN, M DE LEVAL, AND J STARK
}

Thoracic Unit, The Hospital for Sick Children, London

SUMMARY In 3 infants, severe airways obstruction was caused by mediastinal lesions which were not evident on the antero-posterior chest radiograph. Their presence was demonstrated by barium swallow examination. Each infant had thoracotomy carried out urgently. Duplication cysts (without associated cervicodorsal vertebral anomalies) were present in 2 patients and neuroblastoma in the third.
A congenital anomaly compressing the trachea or main bronchus may not be detected at an early stage, despite symptoms. There are two main reasons: (1) the history may be misleading, and (2) there may be nothing on the antero-posterior chest radiograph to suggest that the clinical and radiological features are secondary phenomena.

In cases of stridor, wheezing, or air trapping in the lung, careful scrutiny of the mediastinum for mass 